Check for updates

Cite this: RSC Adv., 2017, 7, 36279

Received 6th June 2017

Accepted 15th July 2017

DOI: 10.1039/c7ra06341e

rsc.li/rsc-advances

\section{LC-MS/MS reveals the formation of aldehydes and iminium reactive intermediates in foretinib metabolism: phase I metabolic profiling}

\begin{abstract}
Adnan A. Kadi, ${ }^{a}$ Sawsan M. Amer, ${ }^{b}$ Hany W. Darwish ${ }^{\text {ab }}$ and Mohamed W. Attwa (D)*ab
Foretinib (GSK1363089) is an inhibitor of multiple receptor tyrosine kinases including MET and VEGFR, with the potential for treatment of solid tumors. In this study, we investigated the in vitro metabolic pathways for foretinib in rat liver microsomes using LC-MS/MS. Methoxylamine and potassium cyanide were used as trapping agents for aldehyde and iminium reactive intermediates, respectively, of foretinib to form a stable complex that can be identified by LC-MS/MS. Six foretinib phase I metabolites were characterized. The phase I metabolic pathways were oxidation, defluorination, reduction and hydroxylation. Additionally, four potential reactive metabolites, two aldehydes and two iminium ions, were found and the bioactivation pathways were proposed. Reporting the in vitro and reactive metabolites of foretinib is very crucial in the development stage. A literature review showed that no previous articles have provided an in vitro metabolism study of foretinib or detailed structural identification of the formed reactive metabolites.
\end{abstract}

\section{Introduction}

Tyrosine kinase inhibitors (TKIs) are considered a very important class of targeted therapy which interferes with specific cell signalling pathways that allow targeting selected malignancies. ${ }^{1}$ Tyrosine kinases are enzymes that catalyze the transfer of the $\gamma$ phosphate of ATP to the tyrosine hydroxyl groups on target proteins. They act as an "on" or "off" switch in many cellular functions. ${ }^{2}$ Strict control of the tyrosine kinase activity in the cell regulates important processes such as the cell cycle, proliferation and cell death. In many cases, the abnormal proliferation characteristics of cancer are driven by growth factor receptor-mediated signaling. In tumor cells, the failure of the control mechanism may lead to excessive phosphorylation, and pathways sustained in an activated state. ${ }^{\mathbf{3} 4}$ Foretinib is a multikinase inhibitor that inhibits multiple receptor tyrosine kinases, including MET (mesenchymal-epithelial transition factor) and VEGFR (vascular endothelial growth factor receptor2 ), with the potential for treatment of solid tumors ${ }^{5}$ and hepatocellular carcinoma (HCC). ${ }^{6}$ Foretinib showed a very promising synergetic effect with HER2 inhibitors and the potential to overcome drug resistance to lapatinib. ${ }^{7}$

Metabolic activation of a drug leading to reactive metabolite(s) that can covalently modify proteins is considered an initial step that may lead to drug-induced organ toxicities.

${ }^{a}$ Department of Pharmaceutical Chemistry, College of Pharmacy, King Saud University, P.O. Box 2457, Riyadh, 11451, Kingdom of Saudi Arabia. E-mail: mzeidan@ksu.edu. sa; Fax: +966114676 220; Tel: +966 114670237

${ }^{b}$ Analytical Chemistry Department, Faculty of Pharmacy, Cairo University, Kasr El-Aini St., Cairo 11562, Egypt
Metabolism is considered a detoxification process by which endogenous compounds and xenobiotics are transformed into more hydrophilic species to enable elimination from the body. In most cases, metabolites are less toxic than parent molecules, but sometimes undergo bioactivation to form reactive intermediates that are more toxic. ${ }^{8-10}$ Reactive metabolites can covalently modify proteins, which are considered the first step in druginduced organ toxicities. ${ }^{11,12}$ The reactive metabolites generated from metabolism are considered crucial in drug-induced toxicity. Usually, reactive metabolites are produced by phase I metabolic reactions. The reactive metabolites can cause many side effects. Reactive intermediates cannot be detected directly due to their transient nature. Instead, a trapping agent was used to capture the reactive intermediate, leading to formation of adducts which are stable and can be detected and characterized by tandem mass spectrometry. ${ }^{\mathbf{1 3 , 1 4}}$<smiles>COc1cc2c(Oc3ccc(N=C(O)C4(C(=O)Nc5ccc(F)cc5)CC4)cc3F)ccnc2cc1OCCCN1CCOCC1</smiles>

Foretinib

Mol. Wt. 632

Fig. 1 Chemical structure of foretinib. 
Foretinib chemical structure contains morpholine group (Fig. 1). Morpholine group containing drugs undergo bioactivation by iminium ion formation or oxidative dealkylation to form aldehyde. ${ }^{15-17}$ GSH or its derivatives are not suitable agents for trapping hard reactive intermediates. Potassium cyanide (KCN) and methoxyl amine are considered perfect trapping agents for iminium ion and aldehydes intermediates, respectively. ${ }^{\mathbf{8}, 15,16}$ The formed adducts are stable and can be separated, detected and characterized using liquid chromatography tandem mass spectrometry. ${ }^{13-15,18,19}$

\section{Chemicals and methods}

\subsection{Chemicals}

Foretinib was procured from LC Labs (Woburn, MA, USA). Ammonium formate and HPLC-grade acetonitrile (ACN), potassium cyanide $(\mathrm{KCN})$, methoxyl amine $\left(\mathrm{MeONH}_{2}\right)$ and formic acid were procured from Sigma-Aldrich (West Chester, PA, USA). Purified water was obtained from Milli-Q plus purification system, Millipore, Waters (Millipore, Bedford, MA, USA). Rat liver microsomes (RLMs) were prepared in-house using Sprague Dowley rat following reported method. ${ }^{20}$

\subsection{Chromatographic conditions}

Study of foretinib fragmentation was performed using an Agilent HPLC 1200 connected to triple quadrupole mass spectrometer (Agilent $6410 \mathrm{QqQ}$ ) by direct injection through using a connector instead of a column. Chromatographic separation for extract of the incubation mixture was performed on an Agilent 1200 series system and an Agilent 6410 QqQ LC/MS with an electrospray ionization (ESI) interface. The chromatography was performed on Agilent eclipse plus $\mathrm{C}_{18}$ analytical column $(150 \mathrm{~mm} \times 2.1 \mathrm{~mm}, 3.5$ $\mu \mathrm{m}$ particle size) (Agilent Technologies, Palo Alto, CA, USA). Column temperature was kept constant at $25 \pm 2{ }^{\circ} \mathrm{C}$. The most suitable chromatographic conditions were achieved at a flow rate of $0.25 \mathrm{~mL} \mathrm{~min}^{-1}$ with a gradient system. Mobile phase consisted of solvent A which is $10 \mathrm{mM}$ ammonium formate ( $\mathrm{pH}$ : 4.2 by addition of formic acid) and solvent $\mathrm{B}$ which is ACN. The stepwise gradient was $5 \% \mathrm{~B}$ (0-5 $\mathrm{min}), 5$ to $70 \% \mathrm{~B}$ (5-60 $\mathrm{min}$ ), 70 to $90 \% \mathrm{~B}$ (60-70 $\mathrm{min}), 90$ to $5 \% \mathrm{~B}(70-75 \mathrm{~min})$. The post time was 15 minutes to allow conditioning of column before the next run.
Sample injection volume was $15 \mu \mathrm{L}$ with a total run time of 75 minutes. Mass parameters were optimized for foretinib. Product ions for foretinib, its phase I metabolites and its adducts were generated in the collision cell by collision-induced dissociation (CID) mode. Detection was performed on a triple quadrupole mass spectrometer, operated with an ESI interface in the positive ionization mode. Low purity nitrogen was used as desolvation gas at a flow rate of $12 \mathrm{~L} \mathrm{~min}^{-1}$ and high purity nitrogen was used as collision gas at a pressure of 55 psi. Source temperature was set at $350{ }^{\circ} \mathrm{C}$ and capillary voltage was set at $4000 \mathrm{~V}$. Fragmentor voltage was set to $145 \mathrm{~V}$ with collision energy of $25 \mathrm{eV}$ for foretinib, its phase I metabolites and its adducts. Mass Hunter software (Agilent Technologies, Palo Alto, CA, USA) was used to control the instruments and data acquisition.

\subsection{RLMs incubations}

Thirty $\mu \mathrm{M}$ foretinib was incubated with $1.0 \mathrm{mg} \mathrm{mL}^{-1} \mathrm{RLMs}$, $1.0 \mathrm{mM}$ NADPH and $50 \mathrm{mM} \mathrm{Na} / \mathrm{K}$ phosphate buffer $(\mathrm{pH} 7.4)$ containing $3.3 \mathrm{mM} \mathrm{MgCl}$. The mixtures were incubated at $37{ }^{\circ} \mathrm{C}$ in a shaking water bath for $120 \mathrm{~min}$. The metabolic reaction was initiated by addition of NADPH and terminated by adding $2 \mathrm{~mL}$ of ice-cold ACN. Centrifugation for the incubation mixture (14 $000 \mathrm{rpm}, 10 \mathrm{~min}$ and $4{ }^{\circ} \mathrm{C}$ ) was done to devoid of proteins. The supernatants were removed, evaporated and reconstituted in ACN/ water and transferred to HPLC vial to be injected into Agilent 6410 LC-MS. ${ }^{21,22}$

\subsection{Trapping foretinib reactive metabolites using methoxylamine and potassium cyanide}

The same experiment of RLMs incubation was repeated using $2.5 \mathrm{mM}$ methoxyl amine and with $1.0 \mathrm{mM} \mathrm{KCN}$ to capture reactive iminium and aldehyde intermediates. Incubations were performed in triplicate to confirm the data obtained.

\subsection{Identification of the in vitro foretinib metabolites}

Full mass spectra (MS) scan and product ion (PI) experiment were used to detect of metabolites and adducts of foretinib formed by the in vitro incubations with RLMs. Searching for metabolites in the total ion chromatogram (TIC) of the metabolic extract was done by extracted ion chromatogram (EIC) of
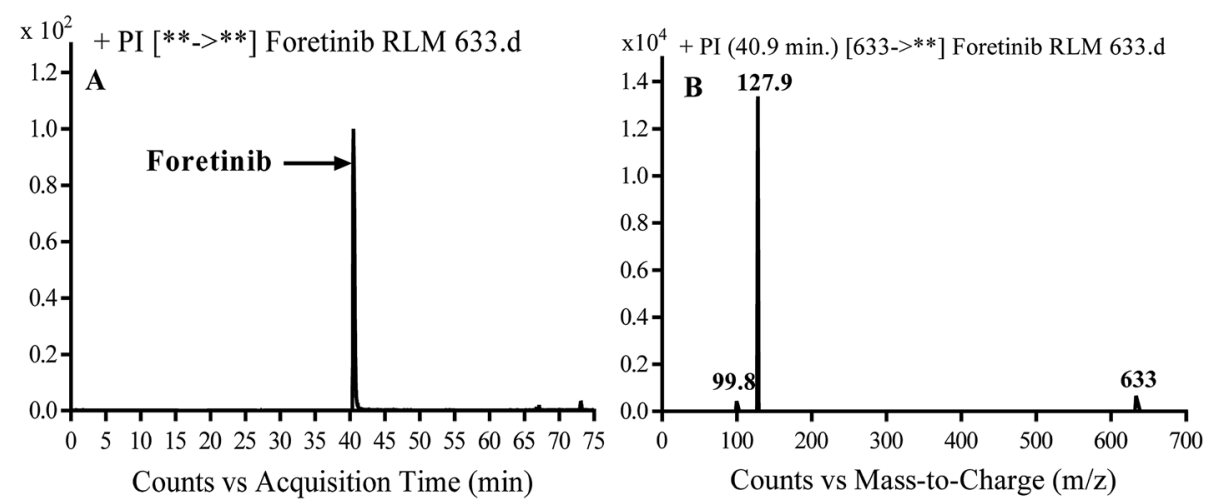

Fig. $2 \mathrm{Pl}$ chromatogram of MIP at $\mathrm{m} / \mathrm{z} 633$ showing foretinib peak at $40.9 \mathrm{~min}$ (A), PI mass spectrum of foretinib (B). 
$\mathrm{m} / \mathrm{z}$ of proposed foretinib metabolites. EICs of the metabolic extract were compared with control incubations.

\section{Results and discussion}

\subsection{PI study of foretinib}

Foretinib molecular ion peak (MIP) appears as $[\mathrm{M}+\mathrm{H}]^{+}(\mathrm{m} / z$ 633) at $40.9 \mathrm{~min}$ in PI chromatogram (Fig. 2A). Collision induced

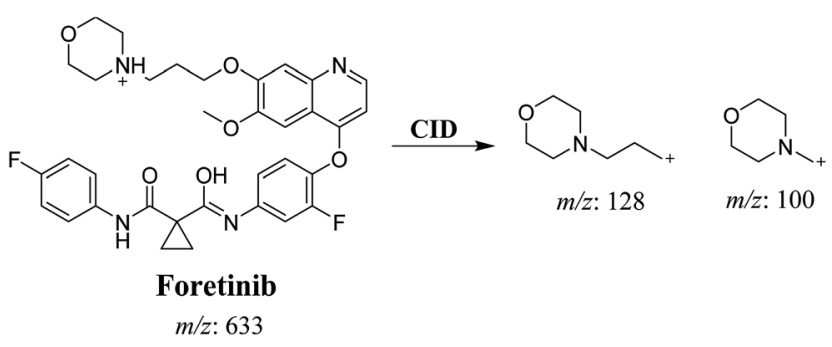

Scheme 1 Proposed CID of foretinib.

Table 1 Phase I and reactive metabolites of foretinib

\begin{tabular}{lllll}
\hline & $\begin{array}{l}\text { MS } \\
\text { scan }\end{array}$ & $\begin{array}{l}\text { Most abundant } \\
\text { fragment ions }\end{array}$ & $\begin{array}{l}\text { Rt. } \\
\text { (min) }\end{array}$ & $\begin{array}{l}\text { Metabolic } \\
\text { reaction }\end{array}$ \\
\hline Foretinib & 633 & $127.9,99.8$ & 40.9 &
\end{tabular}

Phase I metabolites

$\begin{array}{lllll}\text { FA649 } & 649 & 144 & 41.3 & \alpha \text { hydroxylation } \\ \text { FA647 } & 647 & 142 & 45.6 & \alpha \text { oxidation } \\ \text { FA635a } & 635 & 128,99.9 & 40.0 & \text { Reduction } \\ \text { FA635b } & 635 & 506,130,74.1 & 41.9 & \text { Ether cleavage } \\ \text { FA615a } & 615 & 128 & 39.9 & \text { Deflourination } \\ \text { FA615b } & 615 & 128 & 40.8 & \text { Deflourination }\end{array}$

Reactive metabolites

\begin{tabular}{|c|c|c|c|c|}
\hline FC658 & 658 & $631,126,98$ & 51.3 & Cyano addition \\
\hline FC660 & 660 & $633,126,98$ & 51.1 & $\begin{array}{l}\text { Reduction and } \\
\text { cyano addition }\end{array}$ \\
\hline FM591 & 519 & 104 & 51.5 & $\begin{array}{l}\text { Methoxyl amine } \\
\text { oximer formation }\end{array}$ \\
\hline FM607 & 607 & $506,327.1,102.2$ & 37.2 & $\begin{array}{l}\text { Hydroxylation and } \\
\text { methoxyl amine oximer } \\
\text { formation }\end{array}$ \\
\hline
\end{tabular}

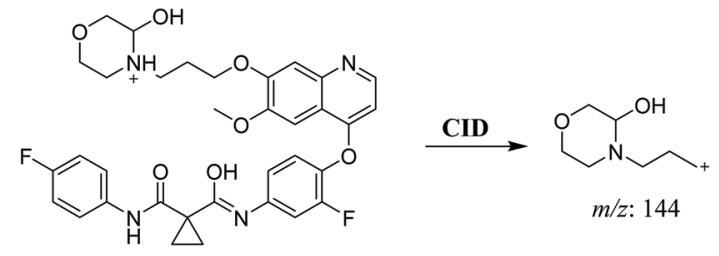

FA649

$m / z: 649$

Scheme 2 Proposed CID of FA649.

dissociation (CID) of parent ion at $\mathrm{m} / \mathrm{z} 633$ gave two daughter ions (DI) at $\mathrm{m} / z 128$ and at $\mathrm{m} / \mathrm{z} 100$ (Fig. 2B). DI at $\mathrm{m} / \mathrm{z} 128$ represents propyl morpholine ring by single bond cleavage (Scheme 1).

\subsection{Identification of in vitro foretinib metabolites produced RLMs incubation}

Purified extracts of RLMs incubations were injected into LCQqQ. Metabolites were not observed in control incubations. Five phase I metabolic reactions generated six metabolites through: $\alpha$ hydroxylation, $\alpha$ oxidation, reduction, ether cleavage and deflourination. Two cyano adducts and two methoxyl amine conjugates were characterized after incubation with RLMs in the presence of $1.0 \mathrm{mM}$ KCN and $2.5 \mathrm{mM}$ methoxylamine, respectively (Table 1 ).

3.2.1. Identification of FA649 phase I metabolite of foretinib. FA649 MIP appears as $[\mathbf{M}+\mathrm{H}]^{+}(\mathrm{m} / z$ 649) at $41.3 \mathrm{~min}$ in PI chromatogram (Fig. 3A). CID of parent ion at $\mathrm{m} / \mathrm{z} 649$ gave one DI at $m / z 144$ which represent propyl hydroxyl morpholine ring by single bond cleavage (Fig. 3B). Hydroxylation was proposed to happen in $\alpha$ position of morpholine nitrogen atom (Scheme 2).

3.2.2. Identification of FA647 phase I metabolite of foretinib. FA647 MIP appears as $[\mathrm{M}+\mathrm{H}]^{+}(\mathrm{m} / \mathrm{z} 647)$ at $45.6 \mathrm{~min}$ in PI chromatogram (Fig. 4A). CID of parent ion at $\mathrm{m} / \mathrm{z} 647$ gave one DI at $m / z 142$ which represent propyl $\alpha$ oxo morpholine ring by single bond cleavage (Fig. 4B). Oxidation was proposed to happen in $\alpha$ position of morpholine nitrogen atom (Scheme 3 ).

3.2.3. Identification of FA635a and FA635b phase I metabolite of foretinib. FA635a and FA635b MIPs appears as [M $+\mathrm{H}]^{+}(\mathrm{m} / \mathrm{z} 635)$ at $40.0 \mathrm{~min}$ and $41.9 \mathrm{~min}$, respectively in PI
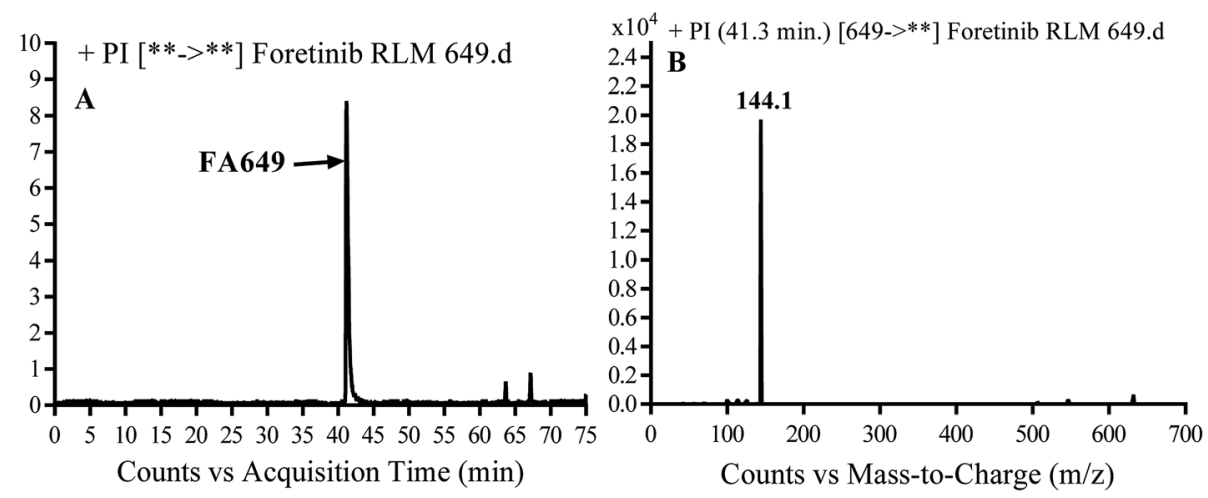

Fig. $3 \mathrm{PI}$ chromatogram of MIP at $\mathrm{m} / \mathrm{z} 649$ showing FA649 peak at $41.3 \mathrm{~min}$ (A), PI mass spectrum of FA649 (B). 

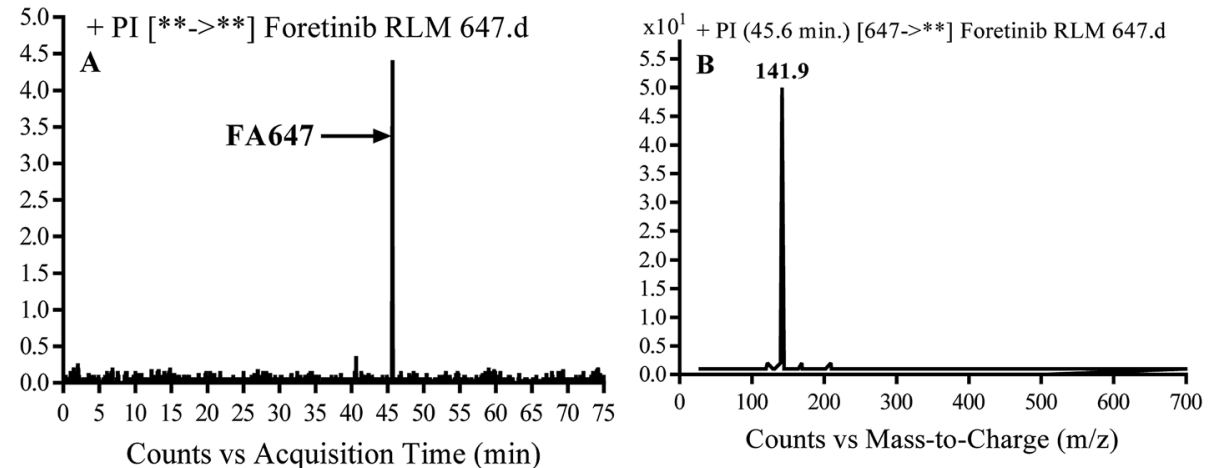

Fig. $4 \mathrm{PI}$ chromatogram of MIP at $\mathrm{m} / \mathrm{z} 647$ showing FA647 peak at $45.6 \mathrm{~min}$ (A), PI mass spectrum of FA647 (B).

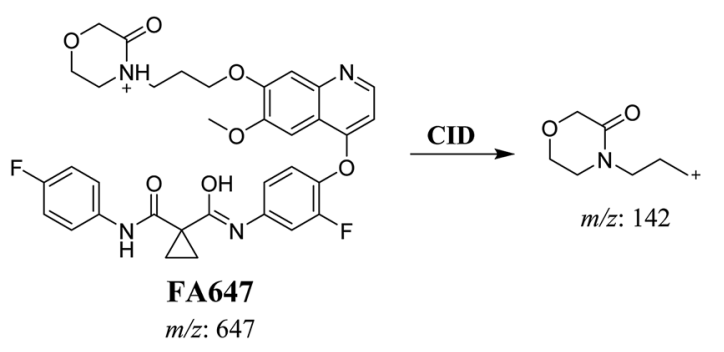

Scheme 3 Proposed CID of FA647.

chromatogram (Fig. 5A). CID of parent ions at $\mathrm{m} / \mathrm{z} 635$ gave different DIs.

In case of FA635a, CID gave two DIs at $\mathrm{m} / \mathrm{z} 128$ and at $\mathrm{m} / \mathrm{z} 100$ (Fig. 5B). DI at $m / z 128$ proposed that no metabolic change occurred in the morpholine ring. DIs revealed that FA635a is reduced form of foretinib without any metabolic change at morpholine ring (Scheme 4).

In case of FA635b, CID gave three DIs at $\mathrm{m} / z$ 506, at $\mathrm{m} / z 130$ and at $\mathrm{m} / \mathrm{z} 74$ (Fig. 5C). DI at $\mathrm{m} / \mathrm{z} 130$ proposed that metabolic change occurred in the morpholine ring which is consistent

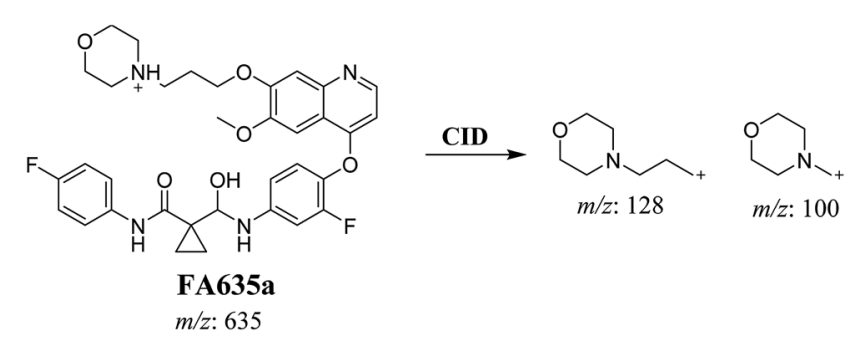

Scheme 4 Proposed CID of FA635a.
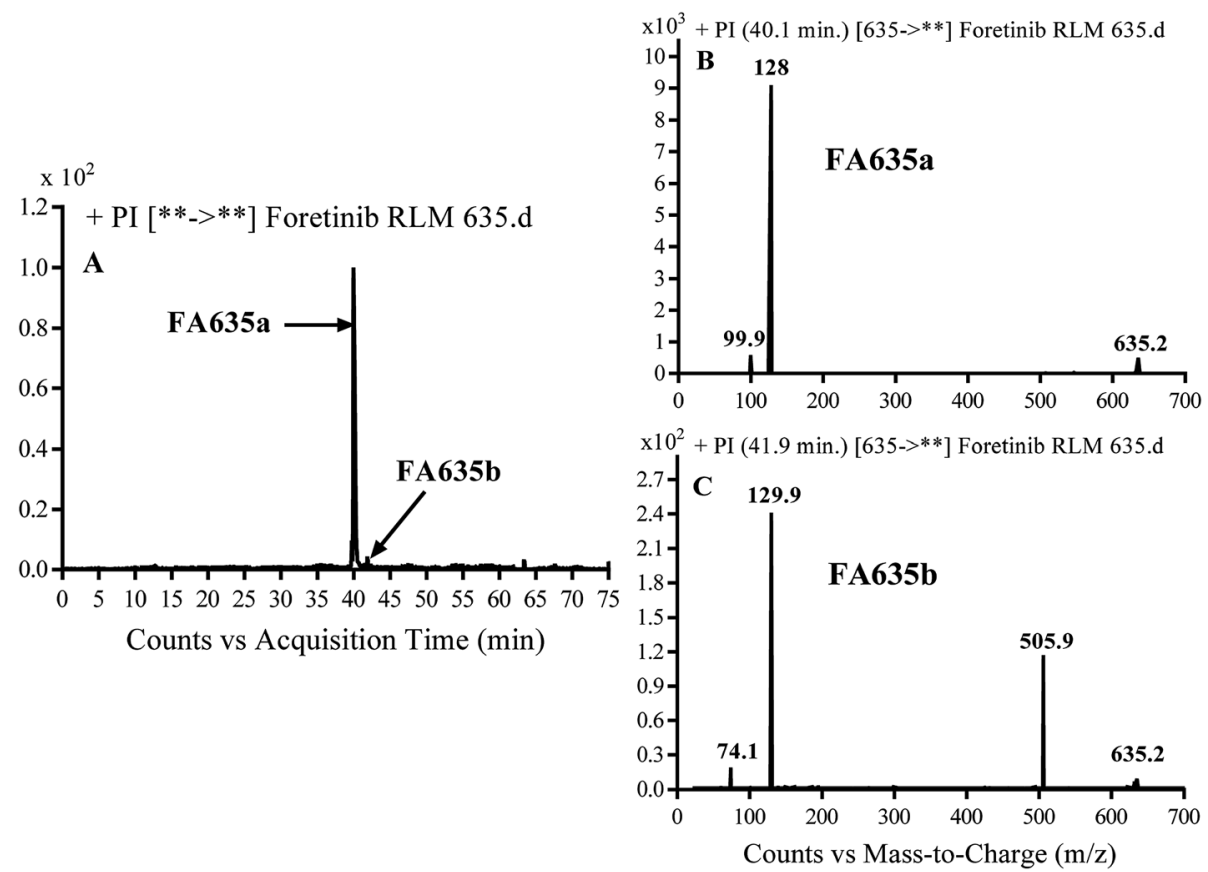

Fig. $5 \mathrm{PI}$ chromatogram of MIP at $\mathrm{m} / \mathrm{z} 635$ showing FA635a peak at $40.1 \mathrm{~min}$ and FA635b peak at 41.9 min (A), PI mass spectrum of FA635a (B), PI mass spectrum of FA635b (C). 


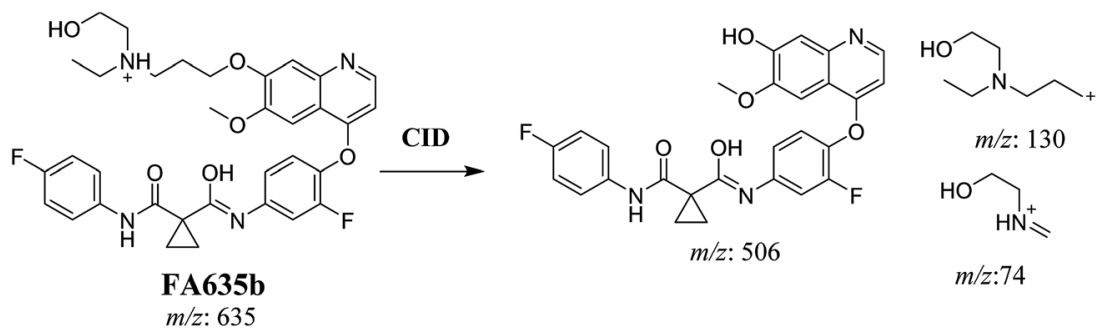

Scheme 5 Proposed CID of FA635b.
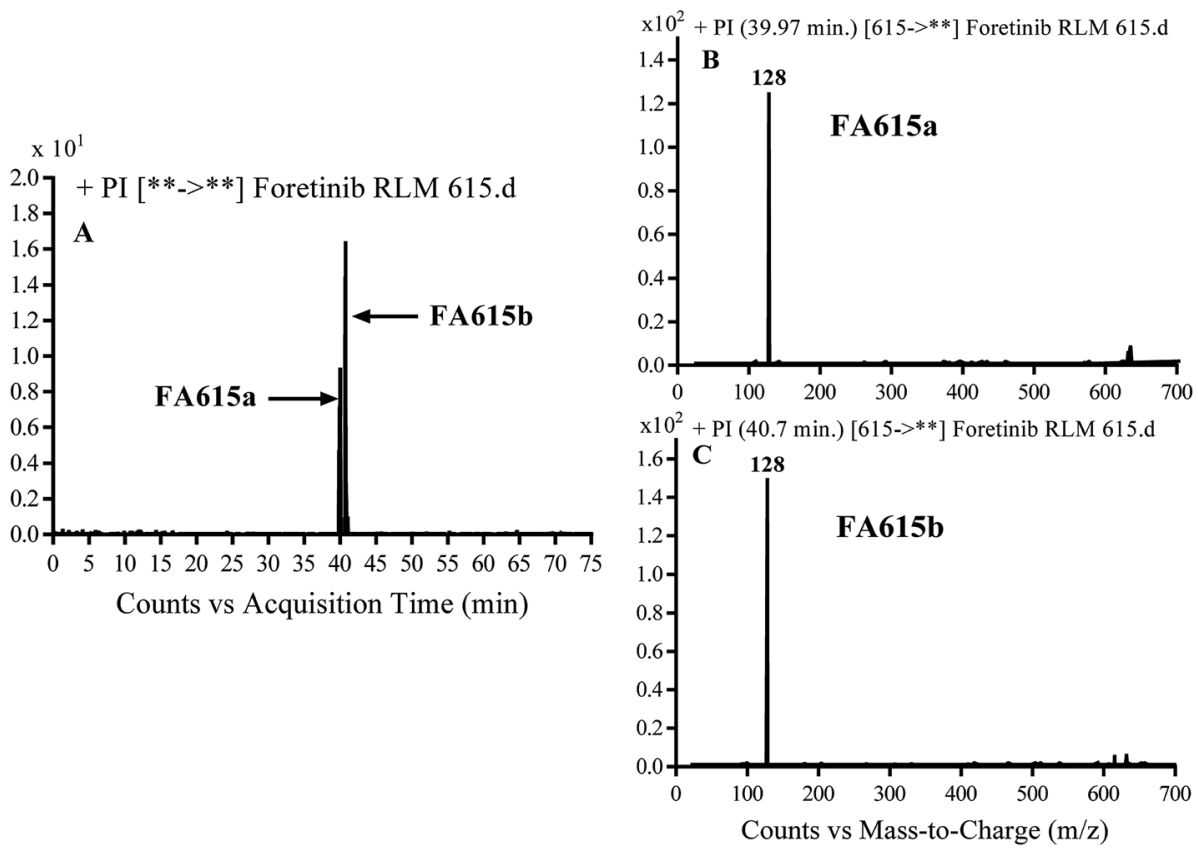

Fig. 6 PI chromatogram of MIP at $\mathrm{m} / \mathrm{z} 615$ showing FA615a peak at 39.9 min and FA615b peak at 41.7 min (A), PI mass spectrum of FA615a (B), PI mass spectrum of FA615b (C).

with the other DI at 506. The DIs revealed that FA635b is the result of ether cleavage and ring opening of morpholine group (Scheme 5).

3.2.4. Identification of FA615a and FA615b phase I metabolite of foretinib. FA615a and FA615b MIPs appears as [M $+\mathrm{H}]^{+}(\mathrm{m} / \mathrm{z} 615)$ at $39.9 \mathrm{~min}$ and $40.8 \mathrm{~min}$, respectively in PI chromatogram (Fig. 6A). CID for FA615a and FA615b gave DI at<smiles>CCCCOc1cc2nccc(Oc3ccc(/N=C(\O)C4(C(=O)Nc5ccccc5)CC4)cc3)c2cc1OCCCN1CCOCC1</smiles>

FA615a or FA615b $m / z: 615$ m/z 128 (Fig. 6B and C) which represent propyl morpholine ring by single bond cleavage. DI at $m / z 128$ proposed that no metabolic change occurred in the morpholine ring. The DIs revealed that the metabolic reaction for FA615a and FA615b is deflourination of one flour atom at two different positions (Scheme 6).

\subsection{Identification of in vitro foretinib reactive metabolites}

Two methoxyl adducts and two cyano conjugates were detected in the case of incubation of foretinib with RLMs and $2.5 \mathrm{mM}$ methoxylamine and $1.0 \mathrm{mM} \mathrm{KCN}$, respectively.

3.3.1. Identification of FC658 cyano conjugate of foretinib. FC658 MIP appears as $[\mathrm{M}+\mathrm{H}]^{+}(\mathrm{m} / \mathrm{z} 658)$ at $51.3 \mathrm{~min}$ in PI chromatogram (Fig. 7A). CID of parent ion at $m / z 658$ gave DIs at $\mathrm{m} / \mathrm{z}$ 631.2, $\mathrm{m} / \mathrm{z} 126$ and $97.8 \mathrm{~m} / \mathrm{z}$ (Fig. 7B). DI at $\mathrm{m} / \mathrm{z} 631$ represented an immediate elimination of a molecule of hydrogen cyanide. Compared to fragmentation pattern of foretinib, DI at $\mathrm{m} / \mathrm{z} 126$ proposed the addition of cyanide ion to morpholine ring as it represented an immediate elimination of a molecule of hydrogen cyanide. In bioactivation of similar morpholine 

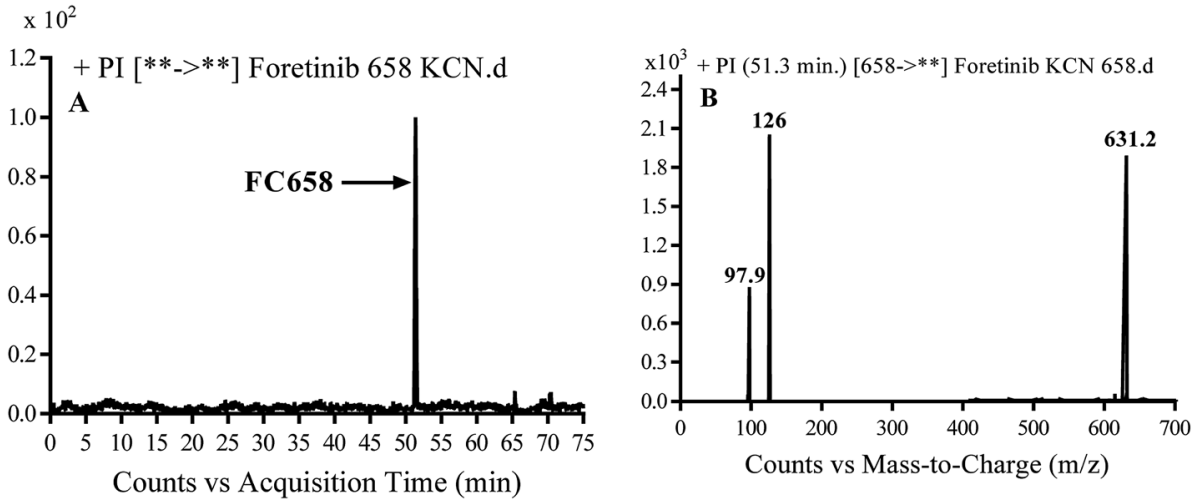

Fig. 7 PI chromatogram of MIP at $m / z 658$ showing FC658 peak at 51.3 min (A), PI mass spectrum of FC658 (B).<smiles>CCCCN1C=COCC1</smiles>

Scheme 7 Proposed CID of FA658.
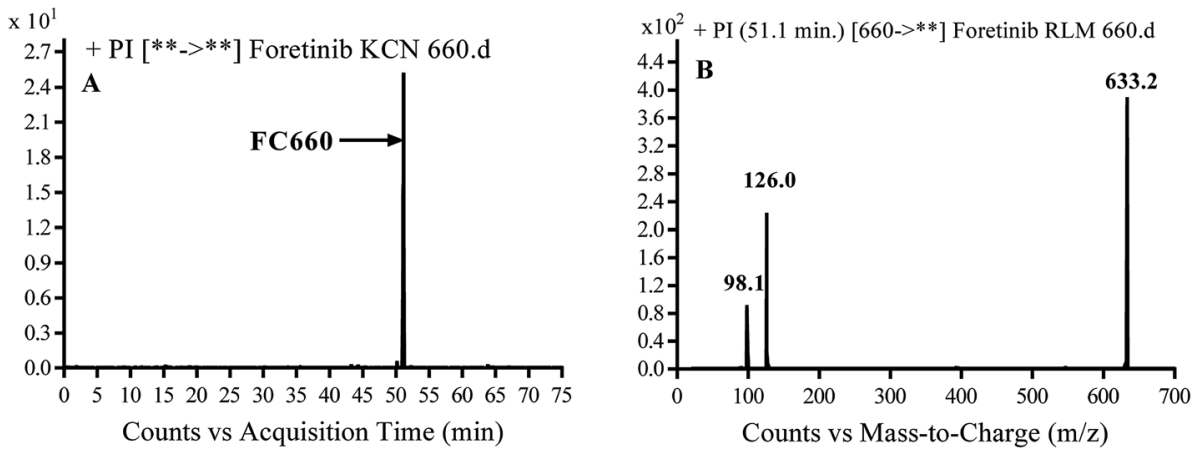

Fig. $8 \mathrm{PI}$ chromatogram of MIP at $\mathrm{m} / \mathrm{z} 660$ showing FC660 peak at $51.1 \mathrm{~min}$ (A), PI mass spectrum of FC660 (B).

containing drugs (cyclic tertiary amine ring), ${ }^{23,24} \alpha$ carbon of the $\mathrm{N}$ atom of morpholine ring was proposed to be bioactivated and attacked by cyanide ion (Scheme 7).
3.3.2. Identification of FC660 cyano conjugate of foretinib. FC660 MIP appears as $[\mathrm{M}+\mathrm{H}]^{+}(\mathrm{m} / \mathrm{z} 660)$ at $51.0 \mathrm{~min}$ in PI chromatogram (Fig. 8A). CID of parent ion at $m / z 660$ gave DIs at<smiles>CCCCN1C=COCC1</smiles>

Scheme 8 Proposed CID of FC660. 

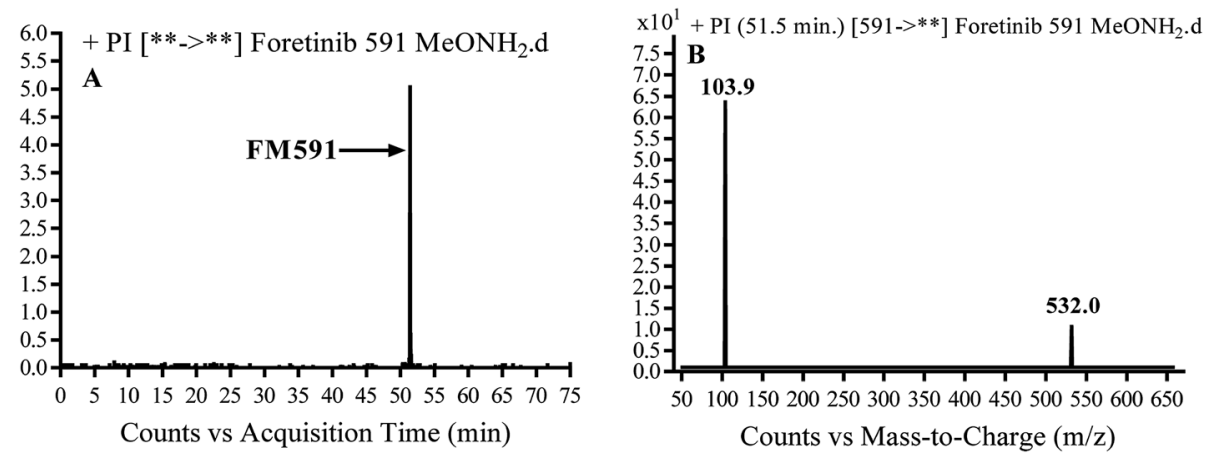

Fig. $9 \mathrm{Pl}$ chromatogram of MIP at $m / z 591$ showing FM591 peak at 51.5 min (A), PI mass spectrum of FM591 (B).

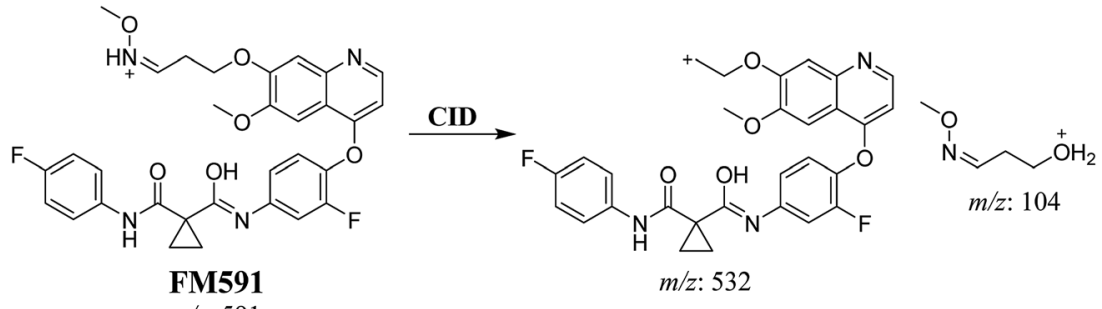

Scheme 9 Proposed CID of FM591.

$\mathrm{m} / z$ 633.2, $\mathrm{m} / \mathrm{z} 126$ and $97.8 \mathrm{~m} / \mathrm{z}$ (Fig. 8B). The DI at $\mathrm{m} / \mathrm{z} 633$ represented an immediate elimination of a molecule of hydrogen cyanide and proposed the reduction of foretinib. The DI at $\mathrm{m} / \mathrm{z} 126$ proposed that the addition of cyanide ion at the activated $\alpha$ carbon of the $\mathrm{N}$ atom of morpholine ring (Scheme 8 ).

3.3.3. Identification of FM591 methoxylamine adduct of foretinib. FM591 MIP appears as $[\mathrm{M}+\mathrm{H}]^{+}(\mathrm{m} / \mathrm{z} 591)$ at $51.5 \mathrm{~min}$ in PI chromatogram (Fig. 9A). CID of parent ion at $\mathrm{m} / z 591$ gave DIs at $\mathrm{m} / z 532.0, \mathrm{~m} / \mathrm{z}$ and $103.9 \mathrm{~m} / \mathrm{z}$ (Fig. 9B). The DI at $\mathrm{m} / \mathrm{z} 532$ proposed the formation of oxime which is consistent with the other DI at $m / z 103.9$ (Scheme 9).

3.3.4. Identification of FM607 methoxylamine adduct of foretinib. FM607 MIP appears as $[\mathrm{M}+\mathrm{H}]^{+}(\mathrm{m} / \mathrm{z} 591)$ at $37.2 \mathrm{~min}$ in PI chromatogram (Fig. 10A). CID of parent ion at $\mathrm{m} / \mathrm{z} 607$ gave DIs at $m / z$ 506.0, $\mathrm{m} / z 327.1$ and $102.2 \mathrm{~m} / z$ (Fig. 10B). The DI at $\mathrm{m} /$ $z 506$ proposed the formation of oxime and all metabolic reactions occurred in propyl morpholine ring. The DI at $m / z 102$ proposed hydroxylation of propyl carbon which is consistent with the other DI at $m / z 327$ (Scheme 10).

\subsection{Proposed pathways of bioactivation of foretinib}

The formation of FC558 and FC660 cyanide conjugates indicated that the formation of iminium intermediates in the morpholine ring. KCN is the perfect trapping agent for iminium. ${ }^{25}$ Hydroxylation of morpholine ring in foretinib then dehydration resulted in formation of iminium ions that are not stable but can be trapped by cyanide forming stable adduct that can be detected in LC-MS/MS (Scheme 11). The pathway of formation of iminium intermediate and foretinib bioactivation
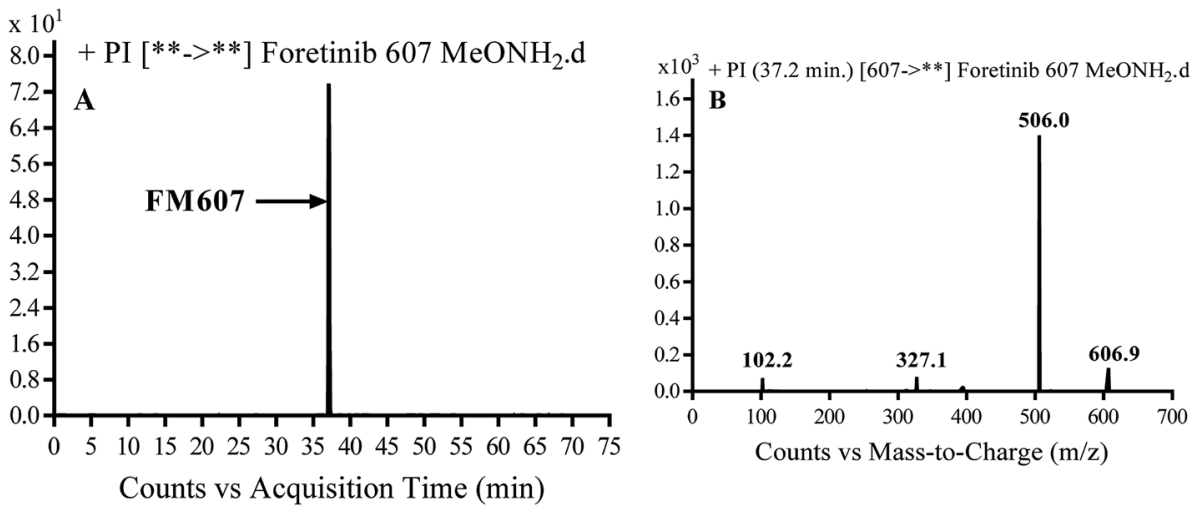

Fig. $10 \mathrm{PI}$ chromatogram of MIP at m/z 607 showing FM607 peak at 37.2 min (A), PI mass spectrum of FM607 (B). 

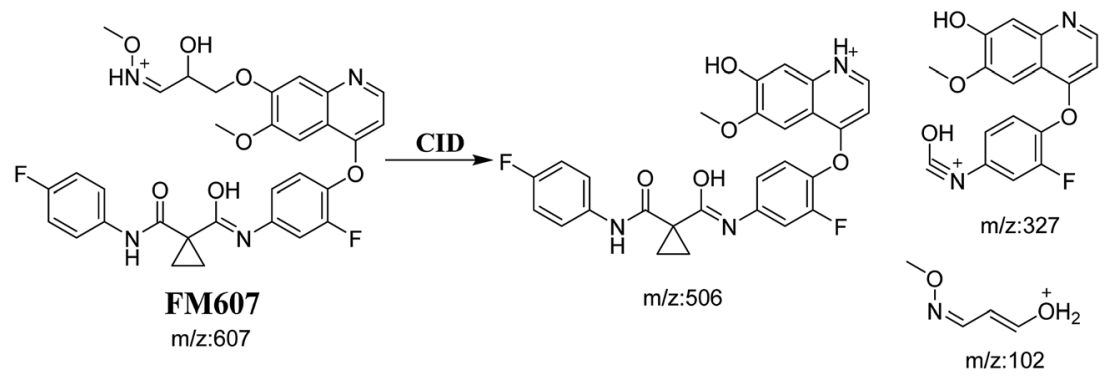

Scheme 10 Proposed CID of FM607.

is previously described with cyclic tertiary amine containing drugs. ${ }^{21,22}$

The formation of FM591 and FM607 indicated that their aldehyde intermediates were generated in the metabolism of foretinib. The aldehyde (FM591) was generated by dealkylation and trapped with methoxylamine to form oxime FM607 was

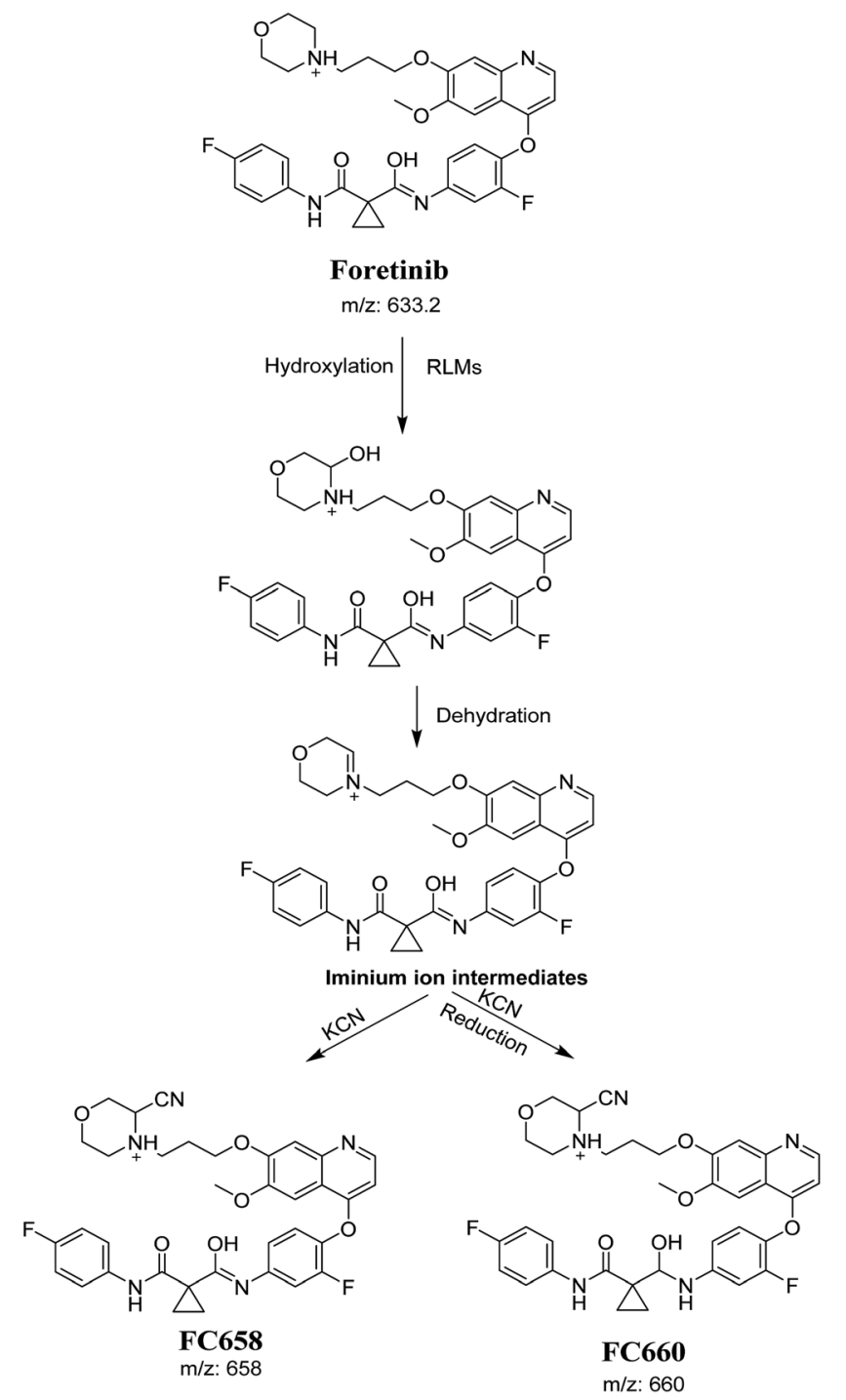

Scheme 11 Proposed pathway of the formation of iminium intermediates and trapping strategy.

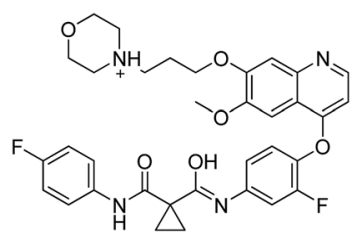

Foretinib

$\mathrm{m} / \mathrm{z}: 633.2$

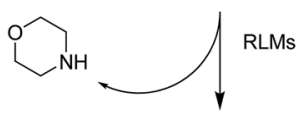<smiles>COc1cc2cccnc2cc1OCCC=O</smiles><smiles>COc1ccc(/N=C2\CCC2(C(=O)Nc2ccc(F)cc2)C(C)(O)C2(C)CC2)cc1F</smiles><smiles>CON/C=C\COc1cc2nccc(Oc3ccc(N=C(O)C(C)(C)C(=O)Nc4ccc(F)cc4)cc3F)c2cc1OCCCN</smiles>

Scheme 12 Proposed pathway of the formation of aldehydes and trapping strategy.

produced in two steps. Foretinib was first hydroxylated then underwent dealkylation to generate aldehyde which was trapped by methoxylamine to form oxime. Both oximes were stable and characterized using LC-MS/MS (Scheme 12). The pathway for formation of aldehyde was described with a morpholine group containing drugs. ${ }^{26}$

\section{Conclusions}

Six phase I foretinib metabolites in addition to four potential reactive metabolites, two aldehydes and two iminium ions, were detected and the bioactivation pathways were proposed 


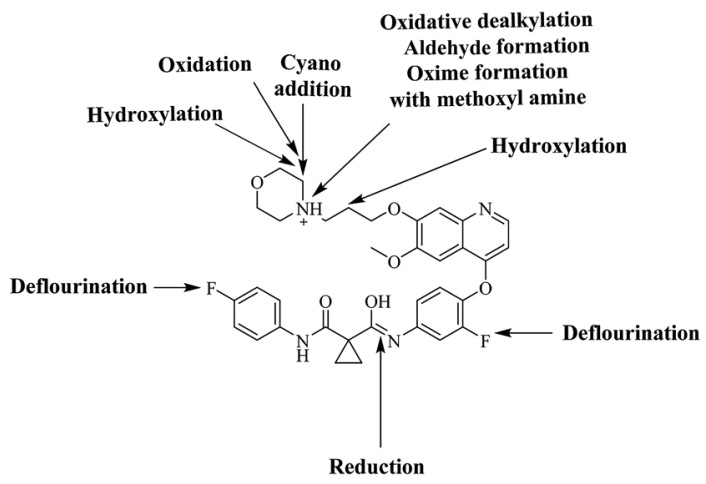

Fig. 11 Chemical structure of foretinib showing places of phase I metabolic reaction and bioactivation pathways.

(Fig. 11). These reactive metabolites may be the reason of foretinib side effects as they are the first step in drug-induced organ toxicities. ${ }^{\mathbf{1 1}, 12}$ This study illuminates the way for further work in the foretinib development and approving to be used in the clinic.

\section{Conflict of interest}

The authors declare no conflict of interest.

\section{Acknowledgements}

"The authors would like to extend their sincere appreciation to the Deanship of Scientific Research at the King Saud University for funding this work through the Research Group Project No. RGP-1437-033."

\section{References}

1 C. Natoli, B. Perrucci, F. Perrotti, L. Falchi and S. Iacobelli, Curr. Cancer Drug Targets, 2010, 10, 462-483.

2 J. Schlessinger, Cell, 2000, 103, 211-225.

3 C. Özvegy-Laczka, J. Cserepes, N. B. Elkind and B. Sarkadi, Drug Resist. Updates, 2005, 8, 15-26.

4 N. Steeghs, J. W. Nortier and H. Gelderblom, Ann. Surg. Oncol., 2007, 14, 942-953.

5 Y. Kataoka, T. Mukohara, H. Tomioka, Y. Funakoshi, N. Kiyota, Y. Fujiwara, M. Yashiro, K. Hirakawa, M. Hirai and H. Minami, Invest. New Drugs, 2012, 30, 1352-1360.

6 D. Rayson, S. Lupichuk, K. Potvin, S. Dent, T. Shenkier, S. Dhesy-Thind, S. L. Ellard, C. Prady, M. Salim, P. Farmer,
G. Allo, M.-S. Tsao, A. Allan, O. Ludkovski, M. Bonomi, D. Tu, L. Hagerman, R. Goodwin, E. Eisenhauer and P. Bradbury, Breast Cancer Res. Treat., 2016, 157, 109-116.

7 M. S. Hsieh, P. W. Yang, L. F. Wong and J. M. Lee, Oncotarget, 2016, 7, 36956-36970.

8 D. C. Evans, A. P. Watt, D. A. Nicoll-Griffith and T. A. Baillie, Chem. Res. Toxicol., 2004, 17, 3-16.

9 A. S. Kalgutkar, D. K. Dalvie, J. P. O'Donnell, T. J. Taylor and D. C. Sahakian, Curr. Drug Metab., 2002, 3, 379-424.

10 U. A. Boelsterli, Curr. Drug Metab., 2002, 3, 439-450.

11 S. R. Knowles, J. Uetrecht and N. H. Shear, Lancet, 2000, 356, 1587-1591.

12 C. Ju and J. Uetrecht, Curr. Drug Metab., 2002, 3, 367-377. 13 S. Ma and M. Zhu, Chem.-Biol. Interact., 2009, 179, 25-37.

14 A. F. Stepan, D. P. Walker, J. Bauman, D. A. Price, T. A. Baillie, A. S. Kalgutkar and M. D. Aleo, Chem. Res. Toxicol., 2011, 24, 1345-1410.

15 L. P. Masic, Curr. Drug Metab., 2011, 12, 35-50.

16 Z. Zhang, Q. Chen, Y. Li, G. A. Doss, B. J. Dean, J. S. Ngui, M. Silva Elipe, S. Kim, J. Y. Wu, F. Dininno, M. L. Hammond, R. A. Stearns, D. C. Evans, T. A. Baillie and W. Tang, Chem. Res. Toxicol., 2005, 18, 675-685.

17 B. K. Park, A. Boobis, S. Clarke, C. E. Goldring, D. Jones, J. G. Kenna, C. Lambert, H. G. Laverty, D. J. Naisbitt and S. Nelson, Nat. Rev. Drug Discovery, 2011, 10, 292-306.

18 S. Ma and R. Subramanian, J. Mass Spectrom., 2006, 41, 1121-1139.

19 A. Tolonen, M. Turpeinen and O. Pelkonen, Drug discovery today, 2009, 14, 120-133.

20 R. von Jagow, H. Kampffmeyer and M. Kinese, NaunynSchmiedebergs Arch. Exp. Pathol. Pharmakol., 1965, 251, 7387.

21 A. A. Kadi, H. W. Darwish, M. W. Attwa and S. M. Amer, $R S C$ Adv., 2016, 6, 72575-72585.

22 S. M. Amer, A. A. Kadi, H. W. Darwish and M. W. Attwa, RSC $A d v .$, 2017, 7, 4479-4491.

23 L. P. Masic, Curr. Drug Metab., 2011, 12, 35-50.

24 N. Castagnoli Jr, J. M. Rimoldi, J. Bloomquist and K. P. Castagnoli, Chem. Res. Toxicol., 1997, 10, 924-940.

25 T. Rousu and A. Tolonen, Rapid Commun. Mass Spectrom., 2011, 25, 1382-1390.

26 X. Liu, Y. Lu, X. Guan, B. Dong, H. Chavan, J. Wang, Y. Zhang, P. Krishnamurthy and F. Li, Biochem. Pharmacol., 2015, 97, 111-121. 